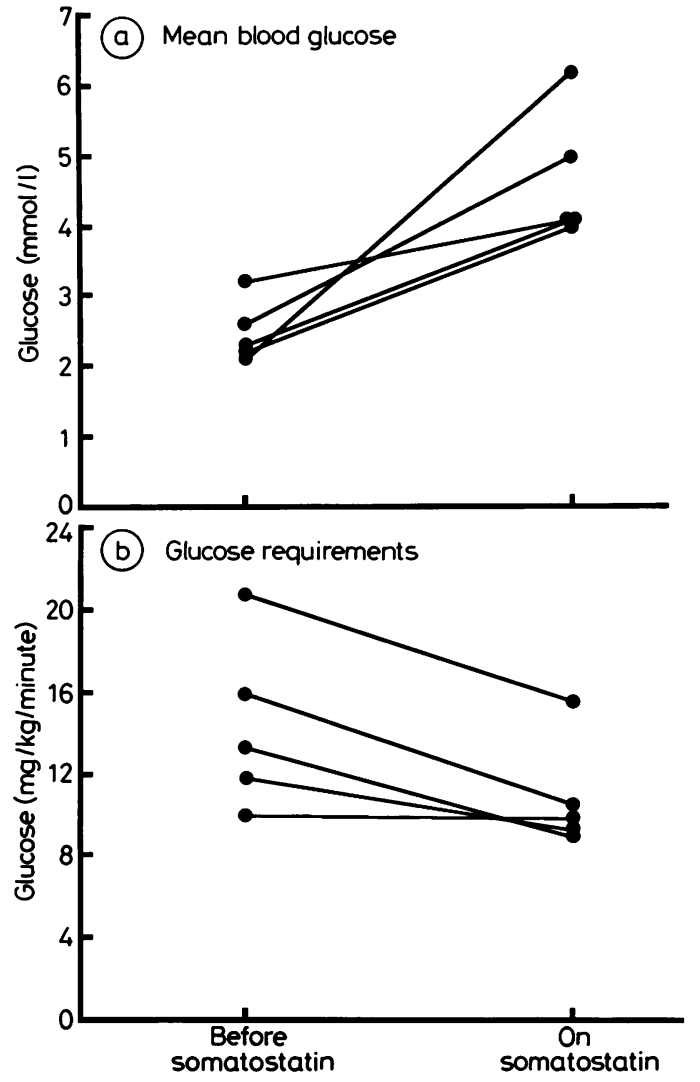

Figure The effect of somatostatin analogue on (a) mean 24 hour blood glucose concentration and (b) 24 hour blood glucose requirements in the five patients.

\section{Discussion}

Somatostatin analogue was effective in the short term management of patients with hypoglycaemia due to hyperinsulinism. We use it to stabilise blood glucose concentrations and to enable lower concentrations of glucose to be used both preoperatively and perioperatively. Given by regular subcutaneous injection its dosage regimen can be easily titrated against response and its short onset of action enables it to be of use in the emergency management of these patients, such as in the resiting of drips.

There are some theoretical reservations about the long term administration of somatostatin analogue to children as it has profound effects on many other hormones. ${ }^{56}$ Until the long term effects of somatostatin analogue are known, the treatment of choice in severe infantile hyperinsulinism should remain surgical, with maximal pancreatectomy. Premedication with somatostatin analogue greatly facilitates blood glucose control during the procedure.

References

1 Aynsley-Green A, Polak JM, Bloom SR, et al. Nesidoblastosis of the pancreas; definition of the syndrome and management of the severe neonatal hyperinsulinaemic hypoglycaemia. Arch Dis Child 1981;56:496-509.

${ }^{2}$ Hirsch HJ, Loo S, Evans N, Crigler JF Jnr, Filler RM, Gabbay HK. Hypoglycaemia of infancy and nesidioblastosis; studies with somatostatin. N Engl J Med 1977;296:1323-6.

${ }^{3}$ Morgan CR, Lazarow A. Immunoassay of insulin; a two antibody system. Diabetes 1963;12:115-26.

${ }^{4}$ Hindmarsh PC, Brook CGD. Short-term management of nesidioblastosis using the somatostatin analogue SMS 201-995. $N$ Engl J Med 1987;316:221-2.

5 Adrian TE, Barnes AJ, Long RG, et al. The effect of somatostatin analogues on secretion of growth, pancreatic and gastro-intestinal hormones. J Clin Endocrinol Metab 1981;53: 675-81.

${ }^{6}$ Aynsley-Green A, Barnes ND, Adrian TE, Kingston J, Boyes S, Bloom SR. Effect of somatostatin infusion on intermediary metabolism and entero-insular hormone release in infants with hyperinsulinaemic hypoglycaemia. Acta Paediatr Scand 1981;70: 889-95.

Correspondence to Dr C G D Brook, Endocrine Unit, Middlesex Hospital, London W1N 8AA.

Accepted 15 July 1988

\title{
Recurrent pancreatoblastoma with inappropriate adrenocorticotrophic hormone secretion
}

\author{
S J PASSMORE, P J BERRY, AND A OAKHILL \\ Bristol Royal Hospital for Sick Children, St Michael's Hill, Bristol
}

SUMMARY We describe a boy with recurrent pancreatoblastoma who developed Cushing's syndrome due to inappropriate adrenocorticotrophic hormone secretion.

Primary epithelial tumours of the pancreas are rare in childhood. Although islet cell tumours have previously been shown to produce inappropriate secretion of peptide hormones, we believe that this is the first report of a pancreatoblastoma producing adrenocorticotrophic hormone and an ectopic hormone syndrome.

\section{Case report}

A 22 month old boy presented with a firm, non- 
tender, asymptomatic abdominal mass of $12 \mathrm{~cm}$ diameter. He was normotensive with a blood pressure of $112 / 75 \mathrm{~mm} \mathrm{Hg}$, normokalaemic with a potassium concentration of $3.6 \mathrm{mmol} / \mathrm{l}$, had an appreciably raised $\alpha$ fetoprotein concentration of $3670 \mu \mathrm{g} / 1$ (normal $2 \mu \mathrm{g} / \mathrm{l}$ ), and a normal serum amylase of $<300$ IU/l (Phadebas method). An ultrasound scan showed a mass of mixed echogenicity crossing the midline and separate from the kidneys. Plain abdominal radiography showed the mass to be focally calcified.

At operation the tumour was found to be arising from the pancreas, and a subtotal pancreatectomy was performed. Histological examination showed a malignant epithelial tumour with areas showing acinar differentiation, areas of poorly differentiated cells with frequent mitoses, and squamoid corpuscles. Immunoperoxidase methods showed strong staining for $\alpha_{1}$ antitrypsin and $\alpha$ fetoprotein, but were negative for adrenocorticotrophic hormone, neurone specific enolase, and chromogranin. Electron microscopy confirmed acinar differentiation; no neurosecretory granules were seen. The appearance was of a pleomorphic pancreatoblastoma. Tumour was present at the line of resection indicating incomplete removal.

There was severe postoperative hypokalaemia (potassium concentration $2.1 \mathrm{mmol} / \mathrm{l}$ ) despite intravenous supplements. The blood glucose remained stable. Treatment was commenced with actinomycin D and vincristine in cycles of three weeks, and the serum $\alpha$ fetoprotein concentration fell to $18 \mu \mathrm{g} / \mathrm{l}$. After three months the concentration of serum $\alpha$ fetoprotein rose; computed tomography and a radionucleide scan using labelled antibody to $\alpha$ fetoprotein showed a tumour deposit in the posterior mediastinum. The chemotherapy was therefore changed to cisplatin/etoposide, ifosfamide/ etoposide, and doxorubicin in cycles of three weeks. The serum $\alpha$ fetoprotein then fell to normal concentrations, and treatment was continued for one year. He remained well off treatment for 18 months.

Three and a half years from first presentation he developed increasing fatigue, weight gain, and pigmentation. On examination he had a Cushingoid appearance, a palpable abdominal mass, and his blood pressure was $130 / 80 \mathrm{~mm} \mathrm{Hg}$. He was hypokalaemic (potassium concentration $2.5 \mathrm{mmol} / \mathrm{l}$ ), and had a raised serum $\alpha$ fetoprotein concentration (590 $\mu \mathrm{g} / \mathrm{l})$. The plasma adrenocorticotrophic hormone concentration was $56 \mathrm{pmol} / \mathrm{l}$ (normal 2-18 pmol/l) and the urinary cortisol $2000 \mathrm{nmol} / 1$ (normal 55-740 $\mathrm{nmol} / \mathrm{l})$. A 24 hour serum cortisol profile showed loss of diurnal variation. Abdominal ultrasound examination confirmed the mass arising from the pancreatic remnant. Chest radiographs showed several metastases. A computed tomogram of brain showed no abnormality of the pituitary fossa and this together with the appreciably raised serum adrenocorticotrophic hormone, skin pigmentation, hypokalaemia, and lack of response to either dexamethasone or metyrapone, confirmed the diagnosis of inappropriate secretion of adrenocorticotrophic hormone. This was recurrent and metastatic pancreatoblastoma, as shown by the recurrent pancreatic mass seen on ultrasound examination and associated with a raised serum $\alpha$ fetoprotein concentration, although histological confirmation was not attempted.

Treatment was resumed with a combination of vinblastine, carboplatin, etoposide, and bleomycin. Unfortunately the tumour showed no response to two courses of chemotherapy, which was therefore withdrawn. The child died three and a half years after diagnosis.

\section{Discussion}

Primary epithelial tumours of the pancreas are rare in childhood, and have a biphasic age distribution. Pancreatoblastoma like other blastomas of childhood affects children in the early years of life, has a slight male predominance, ${ }^{1}$ and is sometimes associated with Beckwith-Wiedemann syndrome. ${ }^{2}$ There have been two previous reports of pancreatoblastoma producing $\alpha$ fetoprotein. ${ }^{3}$ Another tumour, unique to late childhood and early adult life, affects females almost exclusively, and has been given various names including ductuloacinar adenoma and papillary-cystic tumour of the pancreas. It usually follows a benign course.

Pancreatoblastoma can arise in any part of the pancreas and has distinct histological features including undifferentiated areas, acinar differentation, squamoid corpuscles, and the absence (by ordinary light microscopy) of islet cells. Originally thought to arise only from the ventral pancreas and therefore not to contain endocrine cells, it is now known that this tumour may arise in the distal (and therefore from dorsal) pancreas. The latter type seems to have a more insidious clinical onset, is non-encapsulated, and is associated with a worse prognosis.

There have been several reports of islet cell tumours producing hormones such as adrenocorticotrophic hormone, gastrin, glucagon, and growth hormone releasing hormone, ${ }^{4}$ but non-islet cell pancreatic tumours are not associated with inappropriate secretion of peptide hormones. Insulin, gastrin, and somatatostatin have been shown by immunohistochemistry in pancreatoblastoma, ${ }^{56}$ but we believe that this is the first case of pancreatoblas- 
toma producing adrenocorticotrophic hormone and an ectopic hormone syndrome. Although tissue was not available from the recurrent tumour, it is likely that adrenocorticotrophic hormone secretion was the result of endocrine (islet cell) differentiation; this provides further evidence of the ability of this embryonic tumour to differentiate along both exocrine and endocrine lines.

\footnotetext{
References

1 Horie A, Haratake J, Jimi A, Matsumoto M, Ishii N, Tsutsumi Y. Pancreatoblastoma in Japan, with differential diagnosis from papillary cystic tumour (ductuloacinar adenoma) of the pancreas. Acta Pathol Jpn 1987;37:47-63

2 Koh THHG, Cooper JE, Newman CL, Walker TM, Kiely EM,
}

Blum Hoffmann E. Pancreatoblastoma in a neonate with Beckwith-Wiedemann syndrome. Eur J Pediatr 1986;145:435-8.

${ }^{3}$ Iseki I, Suzuki T, Koizumi Y, et al. Alpha-fetoproteinproducing pancreatoblastoma. A case report. Cancer 1986;57: 1833-5.

${ }^{4}$ Lokich J, Bothe A, O'Hara C, Federman M. Metastatic islet cell tumour with ACTH, gastrin, and glucagon secretion. Cancer 1987;59:2053-8.

${ }^{5}$ Buchino J, Castello F, Nagaraj H. Pancreatoblastoma. A histochemical and ultrastructural analysis. Cancer 1984;53: 963-9.

6 Kaishi K, Toyoda N, Kobashi Y, Ueda Y, Matsuo S, Yamabe $\mathrm{H}$. Carconima of the pancreas with endocrine component in childhood. Am J Clin Pathol 1985;83:95-100.

Correspondence to Dr SJ Passmore, Royal Hospital for Sick Children, St Michael's Hill, Bristol BS2 8BJ.

Accepted 5 August 1988

\title{
Intestinal disease in cystic fibrosis
}

\author{
P S BAXTER, ${ }^{*} \mathrm{~J}$ A S DICKSON, $\uparrow \mathrm{S}$ VARIEND, $\ddagger$ AND C J TAYLOR* \\ Departments of *Paediatrics, †Paediatric Surgery, and $\ddagger$ Pathology, The Children’s Hospital, Sheffield
}

SUMMARY Three children with cystic fibrosis developed steatorrhoea unresponsive to changes in pancreatic supplements. The final diagnoses were chronic giardiasis, stagnant loop syndrome, and Crohn's disease. Refractory intestinal symptoms in cystic fibrosis merit further investigation.

It is still controversial whether the gastrointestinal manifestations of cystic fibrosis are primary or secondary, ${ }^{1}$ although recent evidence shows that the basic defect in chloride transport is expressed in the intestinal epithelium. ${ }^{2}$ Steatorrhoea, flatulence, abdominal pain, distal intestinal obstruction syndrome, and rectal prolapse are usually improved by adequate pancreatic supplementation, particularly with microsphere preparations. ${ }^{13}$ Occasionally, however, high doses of these supplements, with or without $\mathrm{H}_{2}$ antagonists, are ineffective. This can be caused by incorrect use of the supplements, or poor compliance, but coeliac disease and cows' milk protein intolerance have also been described in association with cystic fibrosis. ${ }^{1}$ Investigating three children who presented in this way showed further treatable intestinal pathology.

\section{Case reports}

CASE 1

A 16 year old girl in early puberty complained of varying bowel habit over several months, passing up to five loose stools a day, often containing 'blobs of grease'. She also experienced rectal incontinence with laughter, and frequent abdominal pain after food. Her weight gain was poor, but this could not be explained by her chest disease. Stool microscopy showed fat globules but no parasites. At first poor compliance was suspected. A jejunal biopsy specimen, however, showed Giardia lamblia between the villi, and motile trophozoites were seen in the jejunal juice. After a three day course of high dose metronidazole she has been asymptomatic and her weight velocity has increased sharply.

\section{CASE 2}

A 7 year old boy had steatorrhoea, $8 \mathrm{~g} /$ day, despite a low fat diet ( $25 \mathrm{~g} /$ day) and up to 50 pancreatin microsphere capsules per day. His weight was between the 10th and 25th centiles, and height was on the 10th centile. Attempts to introduce a higher fat diet produced abdominal discomfort, distention, flatulence, and gross steatorrhoea. Cimetidine had no effect. As a neonate he had a Bishop Koop resection and ileostomy for meconium ileus, which was closed by clamping at 1 month. A year previously he had been admitted with subacute obstruction, which responsed to conservative management. Concentrations of serum iron, plasma ferritin, and vitamin A were low, and prothrombin time, vitamin $D$, and plasma bile acid concentrations were normal. Xylose absorption and a jejunal biopsy specimen were also normal, but fasting breath hydrogen was increased. Barium enema 